\title{
Prognostic significance of hemoglobin level and autoimmune hemolytic anemia in SARS-CoV-2 infection
}

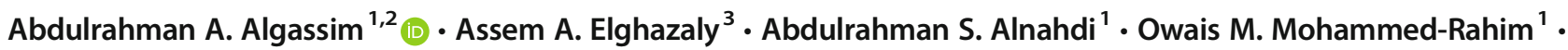 \\ Abdulaziz G. Alanazi ${ }^{1,2}$ - Nawaf A. Aldhuwayhi ${ }^{1,4}$. Mashael M. Alanazi ${ }^{5} \cdot$ Mohammed F. Almutairi $^{5}$. \\ Ibrahim M. Aldeailej ${ }^{5}$. Najeeb A. Kamli ${ }^{5}$. Mahmoud D. Aljurf ${ }^{6}$
}

Received: 25 August 2020 / Accepted: 1 September 2020 / Published online: 12 September 2020

(C) Springer-Verlag GmbH Germany, part of Springer Nature 2020

\begin{abstract}
Higher levels of D-dimer, LDH, and ferritin, all have been associated with the poor prognosis of COVID-19. In a disease where there are acute inflammation and compromised oxygenation, we investigated the impact of initial hemoglobin $(\mathrm{Hgb})$ levels at Emergency Department (ED) triage on the severity and the clinical course of COVID-19. We conducted a cross-sectional study on 601 COVID-19 patients in a COVID-19 national referral center between 13 and 27 June 2020. All adult patients presented at our hospital that required admission or hotel isolation were included in this study. Patients admitted to the intensive care unit (ICU) had a lower initial Hgb than those admitted outside the ICU (12.84 g/dL vs. $13.31 \mathrm{~g} / \mathrm{dL}, p=0.026)$ and over the course of admission; the prevalence of anemia $(\mathrm{Hgb}<12.5 \mathrm{~g} / \mathrm{dL})$ was $65 \%$ in patients admitted to ICU, whereas it was only $43 \%$ in non-ICU patients (odds ratio of 2.464 , 95\% CI 1.71-3.52). Anemic ICU patients had a higher mortality compared with non-anemic ICU patients (hazard ratio $=1.88, \log$-rank $p$ $=0.0104$ ). A direct agglutination test (DAT) for all anemic patients showed that $14.7 \%$ of ICU patients and $9 \%$ of nonICU patients had autoimmune hemolytic anemia (AIHA). AIHA patients had significantly longer length of hospital stay compared with anemic patients without AIHA (17.1 days vs. 14.08 days, $p=0.034)$. Lower Hgb level at hospital presentation could be a potential surrogate for COVID-19 severity.
\end{abstract}

Keywords Anemia $\cdot$ Hemolysis $\cdot$ AIHA $\cdot$ COVID-19 $\cdot$ Prognosis

$\overline{\text { Abdulrahman S. Alnahdi, Owais M. Mohammed-Rahim and Abdulaziz }}$ G. Alanazi contributed equally to this work.

Abdulrahman A. Algassim

A.Algassim@ksmc.med.sa

1 Department of Medicine, King Saud Medical City, Riyadh, Saudi Arabia

2 Department of Medicine, Prince Sultan Military Medical City, Riyadh, Saudi Arabia

3 Department of Hematology and Oncology, King Saud Medical City, Riyadh, Saudi Arabia

4 Department of Medicine, Prince Mohammed Medical City, Sakaka, Al-Jouf, Saudi Arabia

5 Regional Laboratory and Blood Bank, Ministry of Health, Riyadh, Saudi Arabia

6 Oncology Center, King Faisal Specialist Hospital \& Research Centre, Riyadh, Saudi Arabia

\section{Introduction}

Coronavirus disease 2019 (COVID-19) is a recently emerged disease caused by the novel severe acute respiratory syndrome coronavirus 2 (SARS-CoV-2) [1]. COVID-19 has a wide spectrum of manifestations, from asymptomatic infection to complicated pneumonia with acute respiratory distress syndrome (ARDS) [2] together with other extra-pulmonary manifestations [3]. Pneumonia in COVID-19 can be severe resulting in diffuse alveolar damage and disrupting gas exchange [4]. Consequently, arterial oxygenation will be affected, and $\mathrm{O}_{2}$ desaturation will be ensued [5]. Oxygen saturation is a function of hemoglobin $(\mathrm{Hgb})$ concentration, where a decrease in Hgb will result in a decrease in the oxygencarrying capacity and subsequently arterial oxygen content $\left(\mathrm{CaO}_{2}\right)$ [6]. Indeed, anemia alone can lead to critical endorgan ischemia $[7,8]$. As a result, treating anemia will improve $\mathrm{CaO}_{2}$ and subsequently tissue oxygen delivery $\left(\mathrm{DO}_{2}\right)$. 
Accordingly, in some disorders where hemodynamic stability is compromised, treatments achieving higher hemoglobin levels may be required $[9,10]$.

Anecdotal evidence has shown that COVID-19 can cause a progressive decrease in Hgb [11]. Anemia is a known consequence of acute inflammation [12], which results in part from disrupted iron homeostasis and suppression of erythropoietin (Epo) [13]. In COVID-19 patients, iatrogenic active bleeding [14] or secondary to disseminated intravascular coagulation (DIC) can also potentially contribute to anemia [15]. On the other hand, a plethora of reports showed that SARS-CoV-2infected individuals developed autoimmune hemolytic anemia (AIHA) [16-20]. Nevertheless, the prevalence and implications of such findings remain to be elucidated. AIHA is associated with many infections, particularly viral infections. Both warm AIHA and cold agglutinin disease (CAD) have been well described in the pathogenesis of infectionassociated AIHA [21], and both forms have been reported in COVID-19 [17]. All these together, we hypothesized that preexisting low $\mathrm{Hgb}$ levels are associated with worse COVID-19 disease course. Here, we investigate the dynamic relationship between SARS-CoV-2 infection and hemoglobin levels at presentation and during the hospital stay in order to determine the consequences of Hgb levels on COVID-19 and vice versa.

\section{Methods}

\section{Study design and statistical analysis}

This cross-sectional study was conducted at King Saud Medical City (Riyadh, Saudi Arabia). Institutional Review Board (IRB) approval was obtained. We collected patients' data by retrieving medical records using our electronic health system Medisys ${ }^{\circledR}$ HIS (Riyadh, Saudi Arabia). These include patients' age, gender, vitals, laboratory results, length of hospital stay (LoS), and status on discharge. Statistical analysis and graphing were done using Graphpad Prism 8. For continuous variables, mean with standard deviation (sd) or median with interquartile length (iql) was calculated. Comparisons and significance were calculated with two-tailed Student's $t$ test for normally distributed data; otherwise, Mann-Whitney $U$ test is used. For normality testing, we used D'AgostinoPearson and Anderson-Darling tests. For graphic expression, we used mean or median with $95 \%$ confidence interval. Discrete variables were shown as absolute numbers and percentages and analyzed using Fisher's exact test. A simple linear nonparametric correlation between hemoglobin levels and LoS were done. Finally, we used Kaplan-Meier analyses and compared in-hospital survival for anemic and non-anemic patients using the log-rank test (Mantel-Cox). A $p<0.05$ is considered statistically significant.

\section{Patients}

All patients presented to our hospital's Emergency Department (ED) with signs and symptoms of COVID-19 were swabbed and isolated. Patients whose vitals were stable (HR, 60-100; RR, 12-20; $\mathrm{SpO}_{2}>95 \%$ ) and had appropriate environment for home isolation were sent home for isolation. Other than swabbing, no further tests were done. Before being sent home, these patients were instructed on when to seek medical care and how to self-isolate if they were tested positive. They were notified with their test result within $24 \mathrm{~h}$. Patients whose vitals were stable with unsuitable environment for home isolation were provided with hotel rooms. If they were tested positive for SARS-CoV-2, they continued their hotel isolation for 14 days and received occasional medical visits and laboratory tests, including all those related to this study, during the isolation period. Patients whose vitals were unstable were admitted to either general ward $(\mathrm{GW})$ or intensive care unit (ICU), depending on the early warning score (EWS) [22], comorbidities, and laboratory values. Between 13 and 27 June 2020, all adult patients with a positive SARS-CoV-2 PCR result $(n=601)$ from the aforementioned three severity categories (Hotel, GW, and ICU) were included in this study. Admitted patients were followed for 2 more weeks to review their outcomes. In accordance with the World Health Organization (WHO), we defined anemia as having at least one reading of $\mathrm{Hgb}$ level below $12.5 \mathrm{~g} / \mathrm{dL}$ during hospital follow-up.

\section{SARS-CoV-2 PCR}

All patients included in this study were confirmed COVID-19 cases using the RT-PCR cobas ${ }^{\circledR} S A R S-C o V-2$ from Roche (Basel, Switzerland).

\section{Complete blood counts, blood films, and biochemical test}

Complete blood counts (CBC) was done using the UniCel $\mathbb{B}$ DxH 800 analyzer. Liver function test (LFT), renal function test (RFT), and D-dimer were performed using the AU5800 Series Clinical Chemistry Analyzers. Ferritin was done using the UniCel ${ }^{\circledR}$ DxI 800 immunoassay analyzer. All tests are automated and from Beckman Coulter (Brea, CA). Peripheral blood films were made using the Hematek 3000 System from Siemens (Munich, Germany) and slides examined by (K, NA).

\section{Direct agglutination tests}

All COVID-19 patients admitted to the hospital with at least one anemic reading $(\mathrm{Hgb}<12.5 \mathrm{~g} / \mathrm{dL})$ and higher than normal LDH levels were screened for IgG and C3 DAT using 
ORTHO VISION® MAX Analyzer from Ortho Clinical Diagnostics (Raritan, NJ). Patients who were positive for DAT and with a recent history of blood transfusion, autoimmunity or AIHA, or lymphoproliferative disorder were excluded from our analysis.

\section{Results}

In a total of 601 adult patients confirmed by PCR to be infected with SARS-CoV-2 (Fig. 1), the mean Hgb level at ED triage for patients requiring admission was significantly lower than that of patients sent to hotel isolation $(13.08 \mathrm{~g} / \mathrm{dL}$ vs. $13.87 \mathrm{~g} / \mathrm{dL}, p=0.0004$ ) (Fig. 2a). Moreover, among admitted patients, the mean Hgb levels were significantly lower in patients admitted to ICU than in patients admitted to GW (12.84 $\mathrm{g} / \mathrm{dL}$ vs. $13.31 \mathrm{~g} / \mathrm{dL}, p=0.026$ ) (Fig. 2b). Our findings were in line with other well-described predictors of severity, namely, the triage level of platelets $\left(244 \times 10^{9} / \mathrm{L}\right.$ vs. $296 \times 10^{9} / \mathrm{L} p=$ 0.003 ) [23] (Fig. 2c), D-dimer (1.65 mg/L vs. $1.5 \mathrm{mg} / \mathrm{L}, p=$ 0.038 ) [24] (Fig. 2d), LDH (559 U/L vs. $461 \mathrm{U} / \mathrm{L}, p=0.035$ ) [25] (Fig. 2e), and ferritin (961.0 ng/mL vs. $637.0 \mathrm{ng} / \mathrm{mL} p=$ 0.001 ) [26] (Fig. 2f). One hundred sixty-three (65\%) of patients admitted to ICU had anemic readings, whereas, only $111(43 \%)$ of those admitted to GW had readings below $12.5 \mathrm{~g} / \mathrm{dL}$ (Fig. 1) (odds ratio of 2.464, 95\% CI 1.71-3.52) (Fig. 2g). After admission, 93 (37.6\%) ICU patients and 43 $(16.8 \%) \mathrm{GW}$ patients developed anemic readings. The drop in

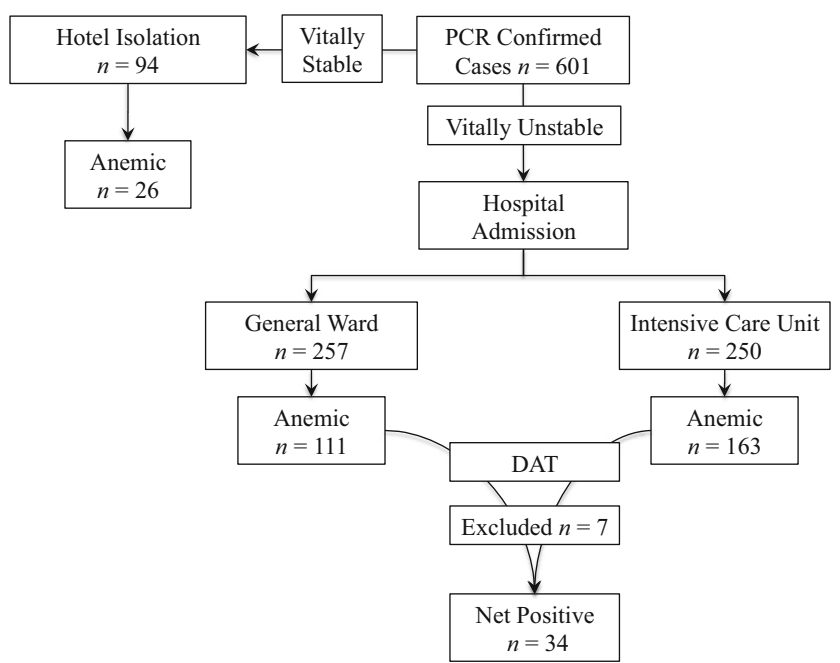

Fig. 1 CONSORT patients flow chart. Patients presented to our facility with respiratory symptoms between 13 and 27 June 2020 were tested for SARS-CoV-2 infection by PCR. Patients with stable vitals were sent for home isolation without further testing whereas those with unstable vitals were admitted. Patients without suitable home for isolation were provided with a hotel room and remained under our supervision. A total of 601 patients with confirmed SARS-CoV-2 infection were investigated for the presence of anemia $(\mathrm{Hgb}<12.5 \mathrm{~g} / \mathrm{dL})$. Anemic patients were screened for autoimmune hemolytic anemia hemoglobin levels was more pronounced in ICU patients ( $12.84 \mathrm{~g} / \mathrm{dL}$ to $9.50 \mathrm{~g} / \mathrm{dL}, p=<0.0001)$ compared with $\mathrm{GW}$ patients (13.31 g/dL to $11.75 \mathrm{~g} / \mathrm{dL}, p=0.0006)$ (Fig. $2 \mathrm{~h}$ ).

There was no statistically significant difference in age or gender between anemic and non-anemic patients (Fig. 3a and data not shown, respectively). To investigate the potential clinical importance of these findings, we examined LoS, as an index for outcome. For GW patients, the mean LoS was significantly longer in anemic patients than in non-anemic patients (13.3 days vs. 10.8 days $p=0.011$ ) (Fig. 3a). A significant negative correlation between $\mathrm{Hgb}$ and LoS was found ( $r=-0.25, p=0.0022$ ). For patients admitted to ICU, because of rapid patients' turnover due to either transfer out of ICU or death, we looked at in-hospital mortality as the final outcome. Survival analysis showed that the mortality rate was significantly higher in anemic patients (75 patients) than in non-anemic patients (19 patients) (Fig. 3b) (log-rank $p=$ $0.0104,95 \%$ CI of hazard ratio 1.145 to 2.774 ).

We also determine the type of anemia based on the mean corpuscular volume (MCV) and found that normocytic anemia was most common among both ICU and GW patients (129 patients at $79.1 \%$ and 79 patients at $71.1 \%$, respectively) (Fig. 4a). Microcytic anemia was more common among GW patients (29 in GW $26.1 \%$ vs. 22 in ICU 13.4\%), while macrocytic was more common among ICU in patients (3 in GW $2.7 \%$ vs. 19 in ICU $7.3 \%$ ). Because of that, we did a direct agglutination test (DAT) for all patients with anemic readings regardless of their initial site of admission. Seven patients were excluded for having a history of blood transfusion within the past 3 months $(n=2)$, history of autoimmunity $(n=2)$, or lymphoproliferative disorder $(n=3)$, all of which could be confounding factors for positive DAT. Among those tested, 34 patients were DAT positive (Fig. 1), all have met our inclusion and exclusion criteria, 10 patients were initially admitted to $\mathrm{GW}$ ( $9 \%$ of GW anemics), and 24 were admitted to ICU (14.7\% of ICU anemics) (Fig. 4b). On determining the type of DAT, only one patient had C3 type alone, while six had both IgG and C3 and 27 had IgG only (Fig. 4c). Among patients with anemic readings, the mean triage $\mathrm{Hgb}$ levels for DAT positive patients were lower than that of those with negative $\operatorname{DAT}(12.21 \mathrm{~g} / \mathrm{dL}$ vs. $13.08 \mathrm{~g} / \mathrm{dL}, p=0.043$ ) (Fig. 4d). Indirect bilirubin level was slightly higher in DAT positive patients (6.1 $\mu \mathrm{mol} / \mathrm{L}$ vs. $5.8 \mu \mathrm{mol} / \mathrm{L})$; however, the difference was not statistical significance (Fig. 4e). Routine peripheral blood films for DAT-positive patients showed spherocytosis, which confirms AIHA (Fig. 4f). No schistocytes were found. Finally, DAT-positive patients had a higher LDH compared with DAT-negative patients $(730 \mathrm{U} / \mathrm{L}$ vs. $620 \mathrm{U} / \mathrm{L} p=0.005)$ (Fig. 4g).

There was no statistically significant difference in age or gender between DAT-positive and DAT-negative patients (Fig. 5a and data not shown, respectively). We found a mortality rate of $32.35 \%$ among DAT-positive patients, while it 
a

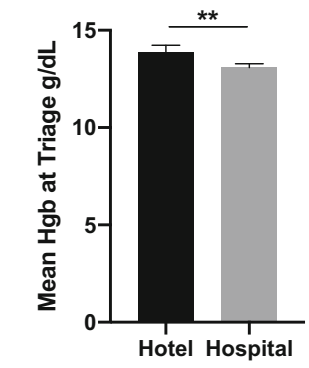

e

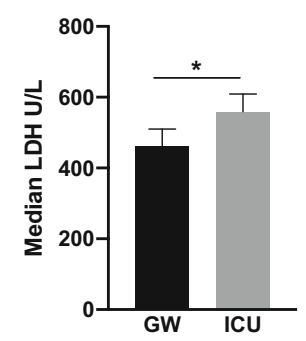

b

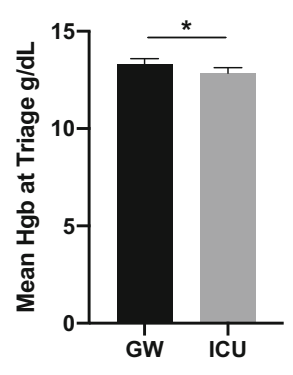

f

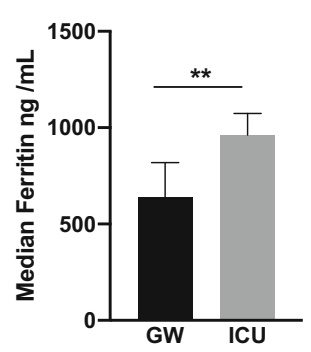

C

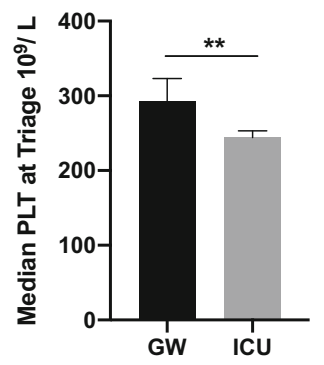

g

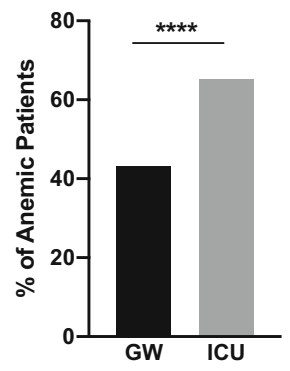

d

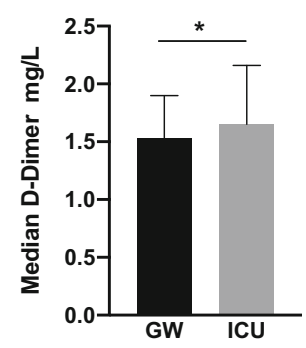

h

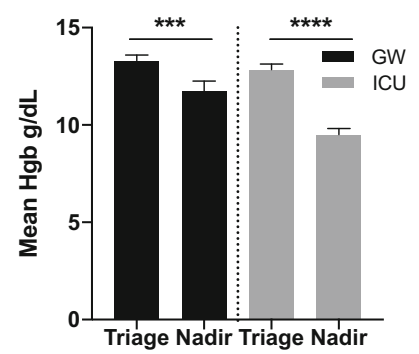

Fig. 2 Hematological parameters at ED triage. a Mean hemoglobin level for patients admitted to the hospital and patients isolated in hotels. $\mathbf{b}$ Mean hemoglobin level for patients admitted in general wards $(\mathrm{GW})$ and patients admitted in intensive care units (ICU). c Median platelets count in GW patients and in ICU patients. d Median D-dimer level in GW patients and in ICU patients. e Median LDH level in GW patients and in ICU

was $26.65 \%$ among DAT-negative patients (Fig. 5b), which was not statistically significant. However, DAT-positive patients had a significantly longer LoS than DAT-negative patients (17.1 days vs. 14.08 days, $p=0.034$ ) (Fig. 5c).

\section{Discussion}

We demonstrate a relationship between hemoglobin level at presentation and the disease course among COVID-19 patients. A lower hemoglobin level is associated with more severe disease course and a higher mortality rate. We also found a progressive dropping of $\mathrm{Hgb}$ levels among admitted

patients. f Median ferritin level in GW patients and in ICU patients. $\mathbf{g}$ Prevalence of anemia $(\mathrm{Hgb}<12.5 \mathrm{~g} / \mathrm{dL})$ among $\mathrm{GW}$ patients and ICU patients. $\mathbf{h}$ Mean hemoglobin level at admission and hemoglobin nadir in GW and ICU patients. *p $<0.05, * * p<0.01, * * * p<0.001$, and $* * * p<<$ 0.0001 . Error bars represent $95 \%$ confidence interval

patients, $37 \%$ of ICU patients and $16 \%$ of GW patients developed anemic readings while in the hospital. This drop in Hgb can be attributed to inflammation associated with COVID-19. In acute inflammation, a decrease in the hemoglobin level is expected due to many complicated mechanisms, the best known among which is cytokines-induced iron metabolism dysregulation and inhibition of Epo formation [12]. In COVID-19 patients, there is also a higher propensity to bleed due to either iatrogenic anticoagulation or DIC; both can be additional contributing factors for the decrease of Hgb. Since ICU patients have a deeper decline in Hgb, our data suggests that the drop is related to the severity of inflammation associated with SARS-CoV-2 infection. Regardless of the inciting

a

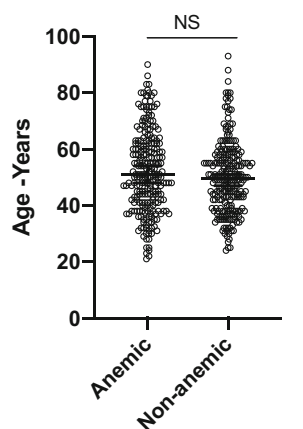

b

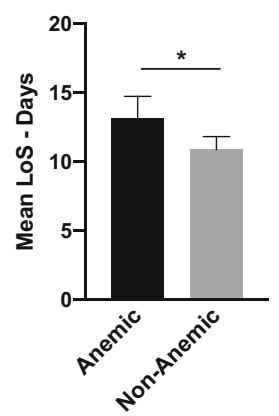

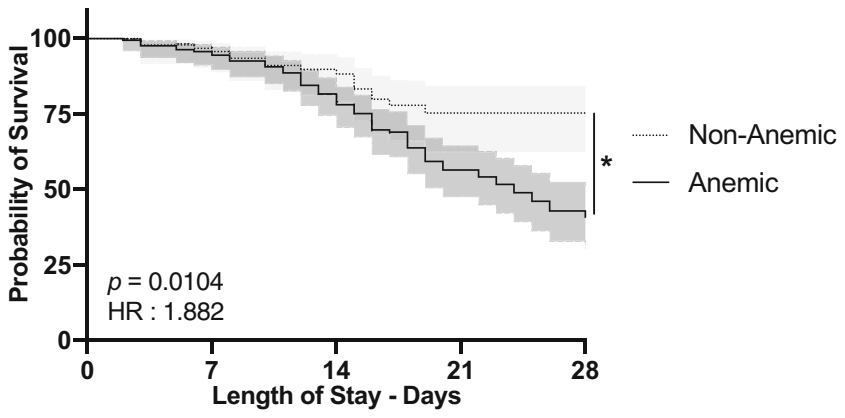

Fig. 3 Outcomes of anemic patients. a Median age of anemic and nonanemic patients. b Mean length of hospital stay (LoS) for patients admitted in GW, anemic indicates patients with $\mathrm{Hgb}<12.5 \mathrm{~g} / \mathrm{dL}$. c Survival analysis for ICU admitted anemic $(\mathrm{Hgb}<12.5 \mathrm{~g} / \mathrm{dL})$ and non-anemic patients. $* p<0.05$ Error bars and shaded areas represent $95 \%$ confidence interval 

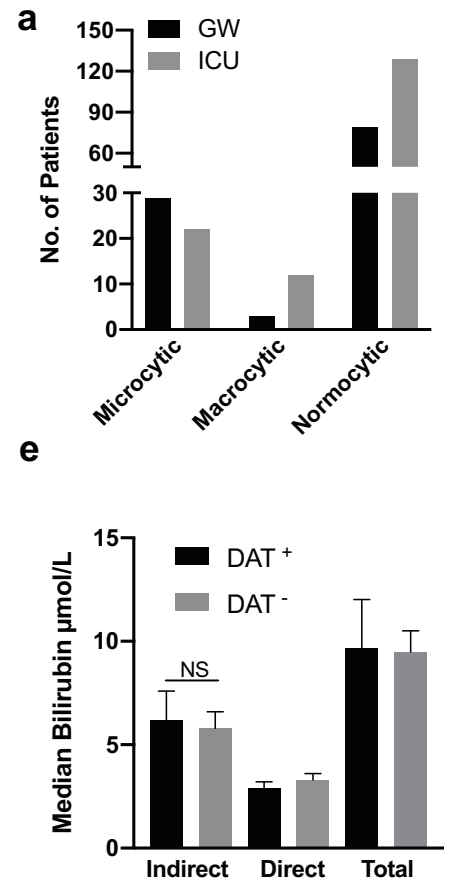

b

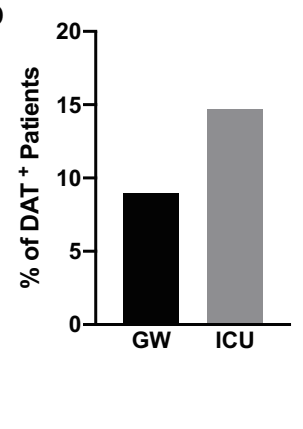

f

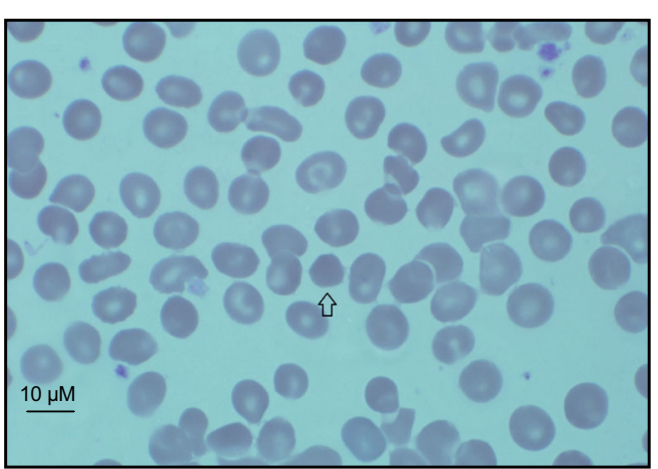

C
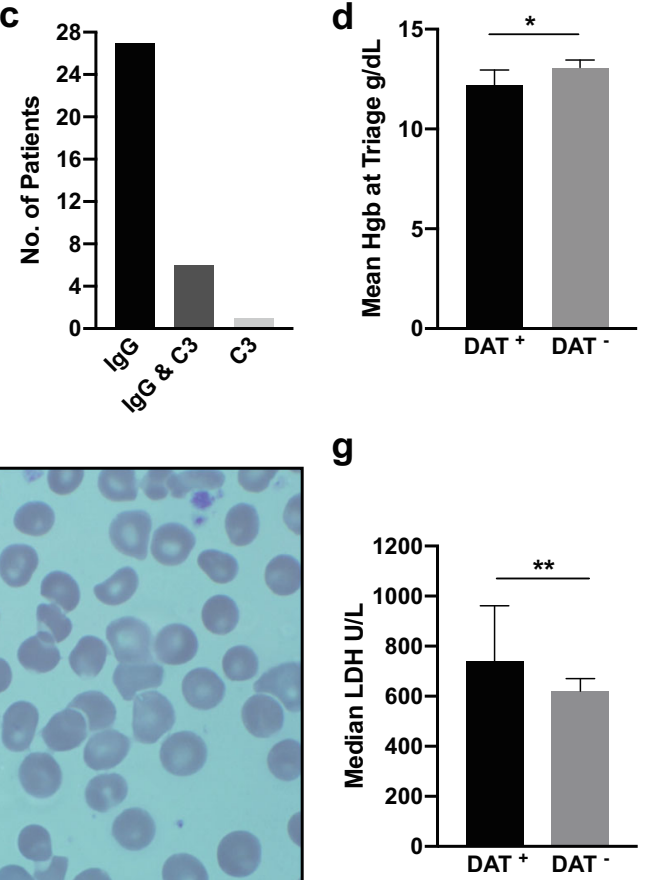

Fig. 4 Types of anemia observed in COVID-19 patients. a Number of anemic patients based on mean corpuscular volume (MCV): microcytic if $<80 \mathrm{fL}$, macrocytic if $>95 \mathrm{fL}$, and normocytic if in between. $\mathbf{b}$ Prevalence of direct agglutinin test (DAT)-positive patients among GW anemic patients $(\mathrm{Hgb}<12.5 \mathrm{~g} / \mathrm{dL})$ and ICU anemic patients. $\mathbf{c}$ Number of patients with the indicated type of DAT reaction. $\mathbf{d}$ Mean hemoglobin level at triage for DAT-positive anemic patients compared with DATnegative anemic patients. e Bilirubin level comparison between $\mathrm{DAT}^{+}$ and $\mathrm{DAT}^{-}$patients. $\mathbf{f} 100 \times$ blood film for anemic patients $(\mathrm{Hgb}=11.1)$, the arrow indicates a spherocyte. $g$ The median level of LDH in DAT positive anemic patients and in DAT-negative anemic patients. ${ }^{*} p$ $<0.05, * * p<0.01$, and error bars represent $95 \%$ confidence interval causes of anemia, we showed a correlation between Hgb levels and LoS in GW patients and a higher mortality rate among ICU anemics.

AIHA is another potential cause of anemia and has been associated with COVID-19. To the best of our knowledge, we are the first to report the prevalence of AIHA among COVID19 patients. We found that $14 \%$ of anemic ICU patients and 9\% of anemic GW patients had positive DAT and spherocytosis. Although we did not measure the haptoglobin level for all of our anemic patients, the presence of spherocytes in blood films is a stronger indicator of AIHA [21]. Interestingly, not only AIHA but also other immune dysregulation phenomena have been reported in COVID-19 patients [27, 28]. Immune thrombocytopenia (ITP) [29], Guillain-Barré syndrome (GBS) [30], and the multi-system inflammatory syndrome [31], all have been described in COVID-19 patients. In our study, the overwhelming presence of the IgG-type rather than the C3-type AIHA suggests a global immune dysregulation rather than a simple IgM cross-reaction [32]. On that same note, we find hemophagocytic lymphohistiocytosis (HLH) is emerging as a recognizable cause of death in SARS-CoV-2 infection [26]. Finally, we showed a mortality rate of $32 \%$ and a longer LoS among anemic DAT-positive patients in comparison with other anemic patients, emphasizing the clinical importance of such a finding. Generally, the demonstration of active AIHA
Fig. 5 Outcomes of DATpositive patients. a The age of DAT-positive anemic patients and of DAT-negative anemic patients, lines represent the median age. b Percentages of death among DAT-positive and DATnegative patients. $\mathbf{c}$ Mean LoS of DAT-positive anemic patients and DAT-negative anemic patients. $* p<0.05$ and error bars represent $95 \%$ confidence interval a

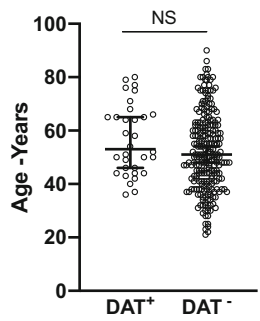

b

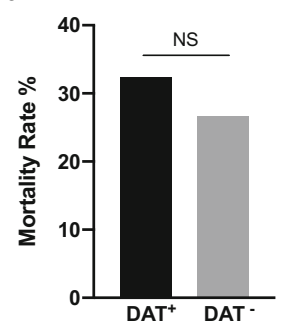

C

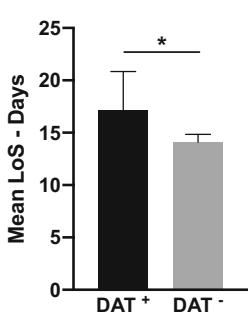


is an indication to start corticosteroids therapy [33, 34]. However, in such a scenario, further investigations are needed.

Although the drop in hemoglobin levels observed in this large cohort of patients is considered clinically mild to moderate, it is likely to augment the arterial $\mathrm{O}_{2}$ content $\left(\mathrm{CaO}_{2}\right)$ decrement. Indeed, acute parenchymal lung injury due to COVID-19 pneumonia will result in a decrease in arterial partial $\mathrm{O}_{2}$ pressure $\left(\mathrm{PaO}_{2}\right)$ and arterial $\mathrm{O}_{2}$ saturation $\left(\mathrm{SaO}_{2}\right)$ [5]. With that, we can extrapolate decline in arterial $\mathrm{O}_{2}$ content $\left(\mathrm{CaO}_{2}\right)=\left(\mathrm{Hgb} \times 1.36 \times \mathrm{SaO}_{2}\right)+\left(0.0031 \times \mathrm{PaO}_{2}\right)$. This decline in oxygen content will result in a decrease in oxygen delivery $\left(\mathrm{DO}_{2}\right)$ and subsequent tissue hypoxia. The Hgb level is a variable in this equation and will affect its outcome. The $\mathrm{Hgb}$ concentration is directly proportionate to $\mathrm{CaO}_{2}$, which is a function of $\mathrm{DO}_{2}$ where $\mathrm{DO} 2=\mathrm{CaO}_{2} \times$ cardiac output $(\mathrm{CO})$ [35].

Based on this mathematical formula, now it is the standard of practice to have a low transfusion threshold when $\mathrm{DO}_{2}$ is compromised. For example, in acute coronary syndrome (ACS) and due to CO compromise, higher targets of $\mathrm{Hgb}$ are required to compensate for $\mathrm{CO}$ deficit as compared with other anemic patients [10]. Those ACS patients with anemic readings tend to have a worse prognosis and correcting anemia will mitigate ACS severity [36, 37]. In acute chest syndrome seen in sickle cell anemia patients, the pathogenesis of $\mathrm{DO}_{2}$ deficit stems from the other variable in the above equation [38]. Rather than the standard restrictive transfusion approach, $\mathrm{CaO}_{2}$ decline in acute chest syndrome is also treated with a liberal blood transfusion in order to achieve a higher Hgb target $[39,40]$. Because COVID-19 patients have decreased $\mathrm{SaO}_{2}$ and $\mathrm{PaO}_{2}$, they therefore have decreased $\mathrm{CaO}_{2}$ and $\mathrm{DO}_{2}$. Moreover, the $\mathrm{Hgb}$ level is a known important player in $\mathrm{DO}_{2}$ pathology. Our study clearly shows that anemic COVID-19 patients have worse prognosis. However, demonstrating that correcting anemia attenuates COVID-19 severity, like in the aforementioned ACS and acute chest syndrome patients, is beyond the scope of this study and requires further work.

Our study provides evidence that lower hemoglobin at presentation is associated with poorer prognosis. Early recognition of those at risk might warrant a lower threshold for earlier and more aggressive medical intervention. Our work is the basis for future investigations on anemia and COVID-19 where anemia is manageable and reversible. The same goes for AIHA where early recognition is necessary as it may require a different approach in management.

Acknowledgments This paper was done with collaborative support from the Department of Medicine and Critical Care Department at King Saud Medical City. We acknowledge Abdulaziz Alrashidi from ED who provided us with data support. Abdullah Ashlowi RN was a case manager and helped us in logistics and coordination. Life Science Editors edited and proofread the manuscript.
Authors' contributions A A A provided study design and data analysis manuscript writing. A A E and M D A contributed valuable ideas and consultations throughout the study. A S A, O M R, A G A, and N A A were data collector. M M A, M F A, and I M A were responsible for direct agglutination test. N A K examined blood films for (DAT positive) patients. All authors have contributed to manuscript review and editing.

\section{Compliance with ethical standards}

Conflict of interest The authors declare that they have no conflict of interest.

Ethical approval All procedures performed in studies involving human participants were in accordance with the ethical standards of the institutional and national research committee and with the 1964 Helsinki declaration and its later amendments or comparable ethical standards.

Informed consent Informed consent was obtained from all individual participants included in the study.

\section{References}

1. Huang C, Wang Y, Li X, Ren L, Zhao J, Hu Y, Zhang L, Fan G, Xu J, Gu X, Cheng Z, Yu T, Xia J, Wei Y, Wu W, Xie X, Yin W, Li H, Liu M, Xiao Y, Gao H, Guo L, Xie J, Wang G, Jiang R, Gao Z, Jin Q, Wang J, Cao B (2020) Clinical features of patients infected with 2019 novel coronavirus in Wuhan, China. Lancet 395(10223):497506

2. Wang D, Hu B, Hu C, Zhu F, Liu X, Zhang J, Wang B, Xiang H, Cheng Z, Xiong Y, Zhao Y, Li Y, Wang X, Peng Z (2020) Clinical Characteristics of 138 hospitalized patients with 2019 novel coronavirus-infected pneumonia in Wuhan, China. JAMA 323: 1061

3. Gupta A, Madhavan MV, Sehgal K, Nair N, Mahajan S, Sehrawat TS, Bikdeli B, Ahluwalia N, Ausiello JC, Wan EY, Freedberg DE, Kirtane AJ, Parikh SA, Maurer MS, Nordvig AS, Accili D, Bathon JM, Mohan S, Bauer KA, Leon MB, Krumholz HM, Uriel N, Mehra MR, Elkind MSV, Stone GW, Schwartz A, Ho DD, Bilezikian JP, Landry DW (2020) Extrapulmonary manifestations of COVID-19. Nat Med 26(7):1017-1032

4. Carsana L, Sonzogni A, Nasr A, Rossi RS, Pellegrinelli A, Zerbi P, et al (2020) Pulmonary post-mortem findings in a series of COVID19 cases from northern Italy: a two-centre descriptive study. The Lancet Infectious Diseases. https://doi.org/10.1016/S14733099(20)30434-5

5. Grasselli G, Zangrillo A, Zanella A, Antonelli M, Cabrini L, Castelli A, Cereda D, Coluccello A, Foti G, Fumagalli R, Iotti G, Latronico N, Lorini L, Merler S, Natalini G, Piatti A, Ranieri MV, Scandroglio AM, Storti E, Cecconi M, Pesenti A, for the COVID19 Lombardy ICU Network (2020) Baseline characteristics and outcomes of 1591 patients infected with SARS-CoV-2 admitted to ICUs of the Lombardy Region, Italy. JAMA 323:1574

6. Pittman RN. Regulation of tissue oxygenation. Integrated Systems Physiology: From Molecule to Function to Disease. San Rafael (CA); 2011.

7. Saaby L, Poulsen TS, Hosbond S, Larsen TB, Pyndt Diederichsen AC, Hallas J, Thygesen K, Mickley H (2013) Classification of myocardial infarction: frequency and features of type 2 myocardial infarction. Am J Med 126(9):789-797

8. DeFilippis AP, Chapman AR, Mills NL (2019) Lemos JAd, ArbabZadeh A, Newby LK, et al. Assessment and treatment of patients 
with type 2 myocardial infarction and acute nonischemic myocardial injury. Circulation. 140(20):1661-1678

9. Felker GM, Adams KF, Gattis WA, O'Connor CM (2004) Anemia as a risk factor and therapeutic target in heart failure. J Am Coll Cardiol 44(5):959-966

10. Hébert PC, Wells G, Blajchman MA, Marshall J, Martin C, Pagliarello G, Tweeddale M, Schweitzer I, Yetisir E (1999) A multicenter, randomized, controlled clinical trial of transfusion requirements in critical care. N Engl J Med 340(6):409-417

11. Fan BE, Chong VCL, Chan SSW, Lim GH, Lim KGE, Tan GB, Mucheli SS, Kuperan P, Ong KH (2020) Hematologic parameters in patients with COVID-19 infection. Am J Hematol 95(6):E131E1E4

12. Weiss G, Ganz T, Goodnough LT (2019) Anemia of inflammation. Blood. 133(1):40-50

13. Theurl I, Mattle V, Seifert M, Mariani M, Marth C (2006) Weiss Gn. Dysregulated monocyte iron homeostasis and erythropoietin formation in patients with anemia of chronic disease. Blood. 107(10):4142-4148

14. Tang N, Bai H, Chen X, Gong J, Li D, Sun Z (2020) Anticoagulant treatment is associated with decreased mortality in severe coronavirus disease 2019 patients with coagulopathy. J Thromb Haemost 18(5):1094-1099

15. Tang N, Li D, Wang X, Sun Z (2020) Abnormal coagulation parameters are associated with poor prognosis in patients with novel coronavirus pneumonia. J Thromb Haemost 18(4):844-847

16. Rosenzweig JD, McThenia SS, Kaicker S (2020) SARS-CoV-2 infection in two pediatric patients with immune cytopenias: a single institution experience during the pandemic. Pediatr Blood Cancer 67(9):e28503

17. Lazarian G, Quinquenel A, Bellal M, Siavellis J, Jacquy C, Re D, Merabet F, Mekinian A, Braun T, Damaj G, Delmer A, Cymbalista F (2020) Autoimmune haemolytic anaemia associated with COVID-19 infection. Br J Haematol 190:29-31

18. Lopez C, Kim J, Pandey A, Huang T, DeLoughery TG (2020) Simultaneous onset of COVID-19 and autoimmune haemolytic anaemia. Br J Haematol 190:31-32

19. Zagorski E, Pawar T, Rahimian S, Forman D (2020) Cold agglutinin autoimmune haemolytic anaemia associated with novel coronavirus (COVID-19). Br J Haematol 190(4):e183-e4

20. Capes A, Bailly S, Hantson P, Gerard L, Laterre P-F (2020) COVID-19 infection associated with autoimmune hemolytic anemia. Ann Hematol 99(7):1679-1680

21. Gehrs BC, Friedberg RC (2002) Autoimmune hemolytic anemia. Am J Hematol 69(4):258-271

22. Alam N, Hobbelink EL, van Tienhoven AJ, van de Ven PM, Jansma EP, Nanayakkara PW (2014) The impact of the use of the early warning score (EWS) on patient outcomes: a systematic review. Resuscitation. 85(5):587-594

23. Yang X, Yang Q, Wang Y, Wu Y, Xu J, Yu Y, Shang Y (2020) Thrombocytopenia and its association with mortality in patients with COVID-19. J Thromb Haemost 18(6):1469-1472

24. Goshua G, Pine AB, Meizlish ML, Chang CH, Zhang H, Bahel P, Baluha A, Bar N, Bona RD, Burns AJ, dela Cruz CS, Dumont A, Halene S, Hwa J, Koff J, Menninger H, Neparidze N, Price C, Siner JM, Tormey C, Rinder HM, Chun HJ, Lee AI (2020) Endotheliopathy in COVID-19-associated coagulopathy: evidence from a single-centre, cross-sectional study. Lancet Haematol 7: e575-e582
25. Shi J, Li Y, Zhou X, Zhang Q, Ye X, Wu Z, Jiang X, Yu H, Shao L, Ai JW, Zhang H, Xu B, Sun F, Zhang W (2020) Lactate dehydrogenase and susceptibility to deterioration of mild COVID-19 patients: a multicenter nested case-control study. BMC Med 18(1): 168

26. Mehta P, McAuley DF, Brown M, Sanchez E, Tattersall RS, Manson JJ, HLH Across Speciality Collaboration, UK (2020) COVID-19: consider cytokine storm syndromes and immunosuppression. Lancet. 395(10229):1033-1034

27. Tay MZ, Poh CM, Renia L, MacAry PA, Ng LFP (2020) The trinity of COVID-19: immunity, inflammation and intervention. Nat Rev Immunol 20(6):363-374

28. Cappello F (2020) Is COVID-19 a proteiform disease inducing also molecular mimicry phenomena? Cell Stress Chaperones 25(3): 381-382

29. Bomhof G, Mutsaers P, Leebeek FWG, Te Boekhorst PAW, Hofland J, Croles FN et al (2020) COVID-19-associated immune thrombocytopenia. Br J Haematol 190:e61-e64

30. Toscano G, Palmerini F, Ravaglia S, Ruiz L, Invernizzi P, Cuzzoni MG, Franciotta D, Baldanti F, Daturi R, Postorino P, Cavallini A, Micieli G (2020) Guillain-Barre syndrome associated with SARSCoV-2. N Engl J Med 382(26):2574-2576

31. Cheung EW, Zachariah P, Gorelik M, Boneparth A, Kernie SG, Orange JS, Milner JD (2020) Multisystem inflammatory syndrome related to COVID-19 in previously healthy children and adolescents in New York City. JAMA. 324:294

32. Angileri F, Légaré S, Marino Gammazza A, Conway de Macario E, Macario AJL, Cappello F (2020) Is molecular mimicry the culprit in the autoimmune haemolytic anaemia affecting patients with COVID-19? Br J Haematol 190(2):e92-e3

33. Zanella A, Barcellini W (2014) Treatment of autoimmune hemolytic anemias. Haematologica. 99(10):1547-1554

34. Salama A (2015) Treatment options for primary autoimmune hemolytic anemia: a short comprehensive review. Transfus Med Hemother 42(5):294-301

35. Dunn JO, Mythen MG, Grocott MP (2016) Physiology of oxygen transport. BJA Educ 16(10):341-348

36. Carson JL, Brooks MM, Abbott JD, Chaitman B, Kelsey SF, Triulzi DJ et al (2013) Liberal versus restrictive transfusion thresholds for patients with symptomatic coronary artery disease. Am Heart J 165(6):964-71.e1

37. Sabatine MS, Morrow DA, Giugliano RP, Burton PBJ, Murphy SA, McCabe CH et al (2005) Association of hemoglobin levels with clinical outcomes in acute coronary syndromes. Circulation. 111(16):2042-2049

38. Vichinsky EP, Styles LA, Colangelo LH, Wright EC, Castro O, Nickerson B (1997) Acute chest syndrome in sickle cell disease: clinical presentation and course. Cooperative Study of Sickle Cell Disease. Blood. 89(5):1787-1792

39. Howard J (2016) Sickle cell disease: when and how to transfuse. Hematology Am Soc Hematol Educ Program 2016(1):625-631

40. Emre U, Miller ST, Gutierez M, Steiner P, Rao SP, Rao M (1995) Effect of transfusion in acute chest syndrome of sickle cell disease. J Pediatr 127(6):901-904

Publisher's note Springer Nature remains neutral with regard to jurisdictional claims in published maps and institutional affiliations. 